\title{
An Investigation of the Nature of Information Systems from a Neurobiological Perspective
}

\author{
Lars Taxén
}

\section{Linköping University Post Print}

\section{Tweet}

N.B.: When citing this work, cite the original article.

Original Publication:

Lars Taxén, An Investigation of the Nature of Information Systems from a Neurobiological Perspective, 2015, Gmunden Retreat on NeuroIS 2015.

http://dx.doi.org/DOI 10.1007/978-3-319-18702-0

Postprint available at: Linköping University Electronic Press

http://urn.kb.se/resolve?urn=urn:nbn:se:liu:diva-120081 


\title{
An Investigation of the Nature of Information Systems from a Neurobiological Perspective
}

\author{
Lars Taxén \\ Department of Computer and Information Science, \\ The Institute of Technology, Linköping University, Sweden \\ lars.taxenegmail.com
}

\begin{abstract}
The purpose of this paper is to investigate how ISs may be conceptualized from an individual, neurobiological perspective. The point of departure is the fact that brains evolved to control the activities of bodies in the world. Based on a number of theoretical contributions bordering between the neural and social realms, a novel IS conceptualization emerges as a dialectical unity of functional organs in the brain and the IT artifact. As a consequence, the IS is conceptualized as intrinsically associated with the individual. I discuss implications of this position for epistemology, ontology, and representation, which are all fundamental aspects of IS research. In conclusion, I claim that a neurobiological perspective on IS has a great potential to advance the discussion of the nature of the IS.
\end{abstract}

Keywords: IS conceptualization · activity modalities - functional organs · equipment $\cdot$ joint action · common identifiers $\cdot$ integrationism - epistemology · ontology $\cdot$ representation

\section{Introduction}

The nature of Information Systems (IS) has been a recurrent theme of debate in the IS discipline, so far without reaching closure (see e.g. [1]). It is commonly accepted that IS research lies at the intersection of people, organizations, and technology [2]. However, disagreement remains about how to define a stable foundation from which ISs can be analyzed and exploited in IS design. For example, Lee claims that "Virtually all the extant IS literature fails to explicitly specify meaning for the very label that identifies it. This is a vital omission, because without defining what we are talking about, we can hardly know it" [3, p. 338].

In an attempt to break new grounds for inquiry, the purpose of this paper is to investigate how ISs may be conceptualized from a neurobiological point of departure. Neuroscientific approaches have recently gained increasingly interest recently in, for example, the NeuroIS initiative [4] and social sciences $[5,6,7]$. The investigation takes as a fundamental fact that "the mental is inextricably interwoven with body, world and action: the mind consists of structures that operate on the world via their role in determining action" [8, p. 527]. In order to articulate this position, I will briefly recapitulate a number of contributions, which somehow links the neural and social realms; 
each from a certain perspective. A preliminary integration of these perspectives lends support to a novel conceptualization of an IS as a dialectical unity of functional organs in the brain and the IT artifact. It follows that the IS is intrinsically associated with the individual; there will be as many ISs as there are individuals engaging with the IT artifact. I discuss implications of this position for epistemology, ontology, and representation, which are all fundamental aspects of IS research. In conclusion, I claim that a neurobiological perspective has a great potential to advance the discussion of the nature of the IS.

\section{Some contributions linking mind and action}

The activity modalities - predispositions for coordination

Coordination is imperative for life and action: "I do not see any way to avoid the problem of coordination and still understand the physical basis of life" [9, p. 176]. Thus, it is highly plausible that the phylogenetic evolution of the brain and body has brought about some kind of neurobiological substrate, providing prerequisites for coordinating actions in various situations. One indication is Kant, who argued that perception depends on 'a priori ideas or categories' of space and time. These categories cannot be "seen" or sensed externally. Rather, time and space are modes of perceiving the external environment [10]. Taxén has suggested that the dimensions of time and space are elements in a larger set of predispositions called activity modalities, which are necessary, albeit not sufficient dimensions for coordinating actions [11]. These modalities are:

- Objectivation - attending to an object around which actions are formed.

- Contextualization - foregrounding relevant things and ignoring irrelevant ones.

- Spatialization - orienting oneself spatially in the situation.

- Temporalization - anticipating actions.

- Stabilization - learning which actions work in a certain type of situation.

- Transition - refocusing attention to another situation.

Since the human neurobiological constitution has not changed significantly since the emergence of early hominids some 3.5 million years ago, these modalities are still at play today whenever we need to coordinate actions.

\section{Functional organs}

A key issue is how to conceptualize the relation between phylogenetically evolved morphological features of the brain, and the ontogenetic development of the individual. This problem was a prime concern for the Soviet psychologist Lev Vygotsky and his colleague, the neuropsychologist Alexander Luria. A common tenet in their thinking is that the socio-historical environment an individual encounters during ontogeny, plays a decisive role in the formation of higher mental functions. External, historically formed artefacts such as tools, symbols, or objects "tie new knots in the activity of man's brain, and it is the presence of these functional knots, or, as some people call them 'new functional organs' [...] that is one of the most important features distin- 
guishing the functional organization of the human brain from an animal's brain" [12, p. 31, italics in original]. This means that "areas of the brain which previously were independent become the components of a single functional system" [ibid.].

\section{Equipment}

The emergence of a functional organ can be seen as an equipment constructing process, where an artefact passes from a state of being present-at-hand to ready-at-hand $[13,14]$. In this process, the artefact recedes, as it were, from "thingness" into equipment, when the in-order-to aspect - what the artefact can be used for - takes precedence. Equipment is encountered in terms of its use rather than in terms of its properties. The evolution of artefacts from being present-at-hand to ready-at-hand takes place entirely in the brain of the individual. In this process, the artefact may or may not change, depending on the material properties of the artefact.

\section{Joint action}

When several individuals coordinate their actions to achieve a common goal, they are engaged in 'joint action' according to Blumer [15]. This term refers to the "larger collective form of action that is constituted by the fitting together of the lines of behavior of the separate participants" [ibid., p. 70]. Joint action cannot be interpreted as participants forming identical functional organs and equipments. Rather, occurs through common, external artefacts called "common identifiers", which provide guidance in directing individual acts so as "to fit into the acts of the others" [ibid., p. 71].

\section{Communication}

Concerning communication, which of course is an essential aspect of joint action, the integrationist approach provides a relevant perspective [e.g. 16,17,18,19,20,21]. A central axiom of integrationism is: "What constitutes a sign is not given independently of the situation in which it occurs or of its material manifestations in that situation" [20, p. 73]. This means that "[e]very act of communication, no matter how banal, is seen as an act of semiological creation" [20, p. 80]. Contextualization is fundamental for sign making and use: "No act of communication is contextless and every act of communication is uniquely contextualized" [18 p. 119]. In addition, integrationism views all communication as time-bound. Its basic temporal function "is to integrate present experience both with our past experience and with anticipated future experience" [22].

The rationale of the term 'integrated' is "that we conceive of our mental activities as part and parcel of being a creature with a body as well as a mind, functioning biomechanically, macrosocially and circumstantially in the context of a range of local environments" [19, p. 738]. The first relates to the physical and mental capacities of the individual; the second to practices established in the community or some group within the community; and the third to the specific conditions obtaining in a particular communication situation. 


\subsection{Integrating the perspectives}

The various pieces indicated above may be integrated as follows. Coordination is fundamental for life. The activity modalities denote evolutionary evolved predispositions for coordinating actions. Actions are carried out together with means, which may be intentionally created artifacts. When engaging with means, new 'knots' are tied in the brain, resulting in the development of functional organs. The dialectical unity of the individual and artifact can be seen as an equipment forming process. When working together, individuals are engaged in joint action in which individual lines of behavior are fitted together using common identifiers. Finally, integrationism provides a complementary perspective on communication.

\section{Implications}

\subsection{IS conceptualization}

In the perspective described, the IS is seen as individual equipment being formed in interaction with the IT artifact. The inevitable consequence is that ISs become individual specific. The IT artifact becomes informative only when an individual has made it into equipment for himself. Thus, the IS and the IT artifact are ontologically distinct, albeit dialectically related; they mutually constitute each other, and they do not make sense in isolation from each other. However, the IT artifact remains an artifact; there is no conflation between the individual/social and material as suggested, for example, in the sociomaterial view on IS [see e.g. 23].

\subsection{Epistemology}

Concerning epistemology, the individual is brought to the forefront: "The mind has as one of its principal functions the contextualized integration of present, past and future experience. That is its constructive role in the evolution of humanity. That is where knowledge comes from, the fons et origo. There is no hidden or more basic source [20, p. 161; italics in original]. A similar perspective is provided by Polanyi: "[All] knowing is action - that it is our urge to understand and control our experience which causes us to rely on some parts of it subsidiarily in order to attend to our main objective focally" [24, p. 2].

This implies, for example, that knowledge cannot be converted between tacit and explicit forms as suggested in the widely used SECI model $[25,26]$. The commodity view on knowledge is flawed. Instead of seeing "knowledge" as an object, we need to focus on "knowing" as a process: "every act of speaking, every motion of the pen, each gesture, turn of head, or any idea at all is produced by the cognitive architecture as a matter of course, as a new neurological coordination" [27, pp. 110-111]. 


\subsection{Ontology}

A prominent line of inquiry for developing new theories in the IS area has been to rely on a formal and precise ontology i.e., a "theory about the nature of and makeup of the real world" [28, p. 3]. One such ontology is Bunge-Wand-Weber (BWW), which claims, among other things, that "the world is made of things", and that "things in the world possess properties" [ibid.].

This is in stark contrast to the "ontology" inherent in the neurobiological perspective. The human capability to contextualize implies that we don't experience things as objectively given. The nature of an object is "constituted by the meaning it has for the person or persons for whom it is an object [15, p. 68]. This meaning is not intrinsic to the object but "arises from how the person is initially prepared to act toward it" [ibid., p. 68-69]. Thus, the world is not "made of things"; neither do these things "possess" properties. Rather, we confer properties onto perceived, actionable objects according to what is relevant in a certain situation.

\subsection{Representation}

Equally prominent in extant IS research is the notion of "representation"; the idea that we possess an "inner world, that is, a coherent system of detached representations that model the world" [29, p. 89]. Representation is seen as "the essence of all information systems" [30, p. viii, italics in original]. The IS "is a representation of a real-world system as perceived by users" [32, p. 88].

However, from a neurobiological point of view, the notion of representation cannot be sustained: "[We] are tempted to say the brain represents. The flaws with such an assertion, however, are obvious: there is no precoded message in the signal, no structures capable of high-precision storage of a code, no judge in nature to provide decisions on alternative patterns, and no homunculus in the head to read a message. For these reasons, memory in the brain cannot be representational in the same way as it is in our devices" [31, p. 77].

\section{Concluding remarks}

This paper is an attempt to instigate a novel line of IS research from a neurobiological perspective. The motivation is simply that any IS approach ultimately need to be anchored in the sine qua non conditions for the existence of human life. To this end, I have pointed to some research contributions, which may contribute to the establishment of a solid foundation for neurobiological conception of ISs. Needless to say, this is just a beginning that has to be corroborated on many areas. However, I claim that a neurobiological perspective has a great potential to significantly advance the discussion of the nature of the IS. 


\section{References}

1. Benbasat, I., \& Zmud, R.W.: The Identity Crisis within the IS Discipline: Defining and Communicating the Discipline's Core. MIS Quarterly. 27(2), 183-194 (2003)

2. Silver, M. S., Markus, M. L., and Beath, C. M.: The Information Technology Interaction Model: A Foundation for the MBA Core Course. MIS Quarterly. 19(3), 361-390 (1995)

3. Lee, A.S.: Retrospect and prospect: information systems research in the last and next 25 years. Journal of Information Technology. 25(4), 336-348 (2010)

4. Dimoka, A; Banker, R.D., Benbasat, I., Davis, F., Dennis, A., Gefen, D., Gupta, A., Ischebeck, A., Kenning, P. H., Pavlou, P. A., Müller-Putz, G., Riedl, R., vom Brocke, J., \&Weber, B.: On The Use of Neurophysiological Tools in IS Research: Developing a Research Agenda for NeuroIS. MIS Quarterly. 36(3), 679-A19 (2012)

5. Ochsner, K. N., and Lieberman. M. D.: The emergence of social cognitive neuroscience. American Psychologist. 56(9) 717-734 (2001)

6. Newman-Norlund, R.D., Noordzij, M.L., Meulenbroek. R.G.J. \& Bekkering, H.: Exploring the brain basis of joint action: Co-ordination of actions, goals and intentions. Social Neuroscience. 2(1), 48-65 (2007)

7. Senior C., Lee, N. \&, Butler, M.: PERSPECTIVE-Organizational Cognitive Neuroscience. Organization Science. 22(3), 804-815 (2011)

8. Love, N.: Cognition and the language myth. Language Sciences. 26(6), 525-544 (2004)

9. Pattee, H.H.: Physical theories of biological coordination. In: M. Grene \& E. Mendelsohn (Eds.) Topics in the Philosophy of Biology, 27 (pp. 153-173). Boston: Reidel (1976)

10. Kant, I.: Critique of pure reason. London: Bell (1924)

11. Taxén, L.: The Activity Modalities: A Priori Categories of Coordination. In: H. Liljenström (ed.), Advances in Cognitive Neurodynamics (IV) (pp: 21-29). Dordrecht: Springer Science+Business (2015)

12. Luria, A. R.: The Working Brain. London: Penguin Books (1973)

13. Heidegger, M.: Being and time. New York: Harper (1962)

14. Riemer, K., and Johnston, R.B.: Rethinking the place of the artefact in IS using Heidegger's analysis of equipment. European Journal of Information Systems 23, 273-288 (2014)

15. Blumer, H.: Symbolic interactionism: Perspective and method. Englewood Cliffs, N.J: Prentice-Hall (1969)

16. Harris, R.: The Language Myth. London: Duckworth (1981)

17. Harris, R.: Signs, language, and communication: Integrational and segregational approaches. London: Routledge (1996)

18. Harris, R.: Introduction to integrational linguistics. Kidlington, Oxford, UK: Pergamon (1998)

19. Harris, R.: Integrationism, language, mind and world. Language Sciences. 26(6), 727-739 (2004)

20. Harris, R.: After epistemology. Gamlingay: Bright Pen (2009).

21. Harris, R.: Introduction to integrational linguistics. Kidlington, Oxford, UK: Pergamon (1998)

22. Harris (n.d.). Integrationism. http://www.royharrisonline.com/integrationism.html

23. Orlikowski, W.J., and Scott, S.V.: Sociomateriality: Challenging the Separation of Technology, Work and Organization. The Academy of Management Annals. 2(1), 433-474 (2008) 
24. Polanyi, M.: Personal knowledge. In: Polanyi, M. and Prosch H. (Eds), Meaning (pp. 2245). Chicago, IL: University of Chicago Press (1975).

25. Nonaka, I. and Takeuchi, H.: The Knowledge-creating Company: How Japanese Companies Create the Dynamics of Innovation. New York: Oxford University Press (1995)

26. Gourlay, S.: Conceptualizing Knowledge Creation: A Critique of Nonaka's Theory. Journal of Management Studies. 43(7), 1415-1436 (2006)

27. Clancey, W. J.: Situated Action: A Neuropsychological Interpretation Response to Vera and Simon. Cognitive Science. 17(1), 87-116 (1993)

28. Weber, R.: Evaluating and Developing Theories in the Information Systems Discipline. Journal of the Association for Information Systems. 13(1), 1-30 (2012)

29. Brinck, I., and Gärdenfors, P.: Representation and Self-Awareness in Intentional Agents. Synthese. 118, 89-104 (1999)

30. Weber. R.: Still Desperately Seeking the IT-artifact. (Editor's Comments). MIS Quarterly, 27(2), iii-xi (2003)

31. Edelman, G. E.: Building a Picture of the Brain. Annals of The New York Academy of Sciences. 882, 1, 68-89 (1999)

32. Wand, Y., and Wang, R. Y.: Anchoring Data Quality Dimensions in Ontological Foundations. Communications of the ACM. 39(11), 86-95 (1996) 